\title{
El giro hacia los saberes excluidos
}

\begin{abstract}
Resumen: La epistemología positivista de la educación toma el saber científico-natural como modelo referente paradigmático para pensar la objetividad, la neutralidad, la intersubjetividad, universalidad, nomoteticidad, rigurosidad, y certeza de los saberes. Esos saberes que no clasifican bajo este criterio son interiorizados y estigmatizados, en tanto se les niega el acceso a esas pretensiones de validez ontológica y gnoseológica, que se le adjudican al saber científico-natural. El artículo tiene como principal objetivo reflexionar sobre el tratamiento epistemológicos de los saberes excluídos. Hoy en día se observa un amplio movimiento intelectual latinoamericano de lengua castellana, que al tiempo que pone en tela de juicio este gesto epistemológico, gira hacia la valorización epistemológica (ontológica y gnoseológica) de esos saberes excluidos: el saber cotidiano, el saber campesino, el saber indígena amerindio, el saber afronegroamericano, y el saber femenino.
\end{abstract}

Palabras clave: Epistemología de la Educación. Violencia epistemológica. Vigilancia epistemológica. Democratización de los saberes.

\section{Introducción}

El sesgo reduccionista epistemológico persiste incluso en autores clásicos del pensamiento epistemológico latinoamericano de lengua castellana que, aunque guardando ciertas distancias con el positivismo, piensan la Epistemología como metaciencia. (BUNGE, 1980; KLIMOVSKY, 1994; MOSTERÍN, 1984; MOULINES, 1982) Ya desde los 90 estas posiciones se observan en publicaciones, donde los autores aplicaron este criterio para definir el objeto y la importancia de la Epistemología de la educación.

En este sentido existe amplio consenso acerca de que la Epistemología es importante para la formación de profesores de ciencias. (GAETA; ROBLES, 1990; GERÔNIMO TELLO, 2004) Por lo general este juicio presupone el entendimiento de la Epistemología como fundamento de la Pedagogía y la Didáctica, asumidas como ciencias. En esta dirección se podría citar a Jimenez Lozano (1994) que propuso sustentar la Epistemología de la educación en la concepción de Jean Piaget sobre la Epistemología como teoría de la constitución de los conocimientos válidos de una ciencia particular. Según se sugiere en Bartomeu Fernando y otros (1997) la Epistemología no debe ir más allá de proporcionar claridad, identidad, y racionalidad de la Pedagogía, pero sin pretensiones de mejorar la práctica educativa, ni ofrecer didácticas alternativas ni avanzar modelos curriculares actualizados, tareas a cargo de pedagogos, no de filósofos. En Gonzaléz y Lobo y otros (1999) se
Eduardo Francisco Freyre Roach Universidad Agricola de la Habana freyre.roach2007@gmail.com

Adolfo Ramos Lamar Universidade Regional de Blumenau

ajemabra@yahoo.com.br 
presenta a la Epistemología de la educación como saber crítico de la Pedagogía. En la década posterior tenemos a Adúriz-Bravo (2001) que defendió la tesis sobre la Epistemología de la educación como metaciencia direccionada hacia la Didáctica de las ciencias. Árraga de Montiel y Añez de Bravo (2003) en su análisis epistemológico del saber didáctico definieron la epistemología como teoría del conocimiento, pero entendida como teoría de la ciencia o del conocimiento científico sistematizado, socializado, válido, universal e intersubjetivo. Abarca Fernández (2001) se refieren a una "Epistemología Pedagógica", en la medida que estudia la complejidad interna de la Pedagogía. Desde el punto de vista de Leal Zambrano (2006), los referenciales epistemológicos son importantes para la reflexión en la Didáctica sobre la génesis, la credibilidad científica y la eficacia práctica de las Ciencias de la Educación. Rincón Ramírez (2004) le asignó a la Epistemología el papel de resolver las indefiniciones y confusiones epistemológicas de la Pedagogía.

Este matrimonio Epistemología-Metaciencia-Pedagogía-Didáctica arrastra consigo la concepción del saber científico como objeto de la Epistemología y arrastra consigo la negación de la validez propia y autónoma de los saberes que no son calificados como saberes científicos. El artículo tiene como principal objetivo reflexionar sobre el tratamiento epistemológico de los saberes excluidos. En el presente se observa un conjunto de publicaciones latinoamericanas de lengua castellana que en la pasada década (2000-2010) proponen un giro hacia la valorización epistemológica de esos saberes excluidos: el saber cotidiano o sentido común o corriente, el saber campesino, el saber indígena amerindio, el saber afronegroamericano, y el saber femenino.

\section{Perspectivas de valorización epistemológica de los saberes excluidos}

Desde diferentes perspectivas teóricas dentro y fuera relativamente del campo de la Epistemología se manifiesta este giro hacia la valorización de los saberes excluidos. A continuación se citan algunas contribuciones latinoamericanas de lengua castellana donde se invita a esta perspectiva epistemológica.

Colombo de Cudmani (2003), en su fundamentación de la importancia de la epistemología para los diseños curriculares en física, vinculó los saberes científicos con el consenso social, 1o 
cual, a su modo de ver tributaría al fomento de un aprendizaje significativo en los estudiantes. Perafán Echeverri (2004), propuso que la Epistemología tribute al planeamiento e implementación de cambios en la enseñanza de las ciencias, pero que ha de considerar los saberes basados no solo en las ciencias, sino también en la experiencia y rutinas. Yarza de los Ríos (2005) apuntó hacia la idea de la Epistemología como abordaje teórico sobre el conocimiento, $\mathrm{y}$, en tal sentido, no se toma el conocimiento científico como referente absoluto. Retamoso Rodríguez (2007) alude a una "Epistemología Educacional" orientada a disminuir la 3espontaneidad y el eclecticismo en educación en general.

En De Zan e otros (2007) se aboga por la construcción y validación de los conocimientos en educación, en cuanto involucran líneas de acción. José Rodolfo Henao Gil (1995) considera que la escuela siempre ha tenido entre sus objetivos la procura de la verdad y la certeza a través de la estructura curricular, y no solo del saber científico implicado. Gallego Torres y Gallego Badillo (2007), proponen un modelo de análisis epistemológico del saber didáctiCo, a partir de la caracterización de las razones que 1levaron a las comunidades científicas a la formular y aceptación de los saberes científicos. Por su parte Massé Narváez (2008) sugiere el análisis epistemológico del saber científico-natural y el saber didáctico, como construcciones históricas, sustentadas en las articulaciones no solo con la realidad (totalidad social), sino también con las diversas dimensiones (estructurales y contextuales) de la realidad y la diversidad de disciplinas.

Similar planteamiento se observa en Eschenhagen (2008), cuando analiza los retos epistemológicos del currículo en los cursos de posgrado de medio ambiente, a la luz de la exigencia de la interdisciplinariedad, dado a que el saber ambiental es complejo y construido sociopolíticamente, y condicionado por las relaciones de poder.

Estos autores, como puede observarse, además de indicar que el saber científico se estructura más allá de una supuesta realidad empírica y la competencia metodológica y técnica de los científicos, toman en serio los saberes descalificados como no científicos, y reivindican autonomía, validez, y estatuto en la configuración y funcionamiento de la realidad educativa: significados, experiencias, rutinas, líneas de acción y prácticas sociales de los sujetos. Y esto incentiva a pensar en la concurrencia de esos saberes en pie de 
igualdad con los saberes científicos, tanto en la docencia cotidiana, como en la investigación educacional, y los textos docentes.

Esta valorización se realiza desde diferentes perspectivas dentro del campo específico de la Epistemología de la educación, que entroncan y confluyen en el gesto antipositivista de corte antipositivista. (OROZCO CRUZ, 1998; UNIVERSIDAD PEDAGOGICA NACIONAL, 2001) Se destaca en este sentido los autores que trabajan con el paradigma fenomenológico-hermenéutico, emergente de los trabajos de Edmund Husserl, Martin Heidegger, Paúl Ricoeur, etc. Quienes en Epistemología de la educación asumieron este referencial o paradigma, abogaron por la consideración del "mundo de la vida" y la experiencia instropectiva, intersubjetiva, vivencial, emocional, significativa, interpretativa, y performativa de los sujetos involucrados histórica y cotidianamente en la realidad educativa, incluyendo al investigador de la educación. Esta perspectiva epistemológica fue desarrollada por los proponentes de la Tratado de hermenéutica analógica (ARRIARÁN, 2007; BEUCHOT, 1997; BEUCHOT; PRIMERO RIVAS, 2003; HERNÁNDEZ GARCÍA, 2007), en cuyos trabajos se habla de una Epistemología de la educación que no sea ni unívoca ni equívoca, ni objetivista ni subjetivista, ni absolutista ni relativista ni universalista ni particularista, y donde se asuma como premisa fundamental el respeto, la comunicación, la comprensión y el interaprendizaje entre las diversas culturas y saberes en lo histórico y cotidiano escolar.

Los autores que adoptaron la Epistemología crítico-dialéctica, que se derivó de Jürguen Habermas, sugirieron la sustitución de la racionalidad instrumental, tecnocrática, y monológica en educación, por un concepto de racionalidad discursiva crítica, comunicativa y dialógica, que diera al traste con las asimetrías de poder, con un sentido emancipatorio, de cara a la historicidad de la praxis. Se observa esta perspectiva en Delgado de Colmenares (2002) que llamó a la liberar a los formadores e investigadores de esa racionalidad instrumental, que sirve a la reproducción y manutención del status quo económico y social. Zuluaga (2003) apuntó que esa concepción instrumental se relaciona con el énfasis en la "enseñanza" y en el proceso áulico, y propuso que los saberes han de analizarse como procesos en su historicidad, es decir, con relación al pasado y el presente. Andrade (2005) habla del aprendizaje dialógico. Por su parte, Calzadilla (2006) denuncia que la razón instrumental conlleva a la división social del trabajo universitario, 
a su disonancia con la vida cotidiana, y a la preeminencia de los valores de cambio sobre los valores de uso, y, por ende, a la cosificación del sujeto formador. Este autor termina diciendo que la educación superior, los docentes, los alumnos y las esferas públicas deben hacer posible el encuentro entre el sujeto epistémico y el sujeto práctico, para que se consolide una racionalidad crítica del discurso pedagógico.

En la Epistemología de la educación que se inspiró en el Pensamiento Posmoderno, (Lyotard), se sugiere este gesto epistemológico inclusivo de los saberes excluidos, al proponerse la subversión de los metadiscursos, metarrelatos, metanarraciones, o totalizaciones discursivas que se desprenden proyecto de modernidad. Según Moreno (2000) el pensamiento posmoderno propone el reconocimiento de la multiplicidad de racionalidades, inteligencias, modelos de humanidad, culturas, así como las diferencias, la subjetividad, la incertidumbre, la probabilidad, la parcialidad, y la complejidad de los saberes y métodos. Henao Gil (1995) habló de como los conceptos de verdad y certeza en la perspectiva posmoderna llevan al entendimiento de que no hay verdades ni eternas ni terminales, ni siquiera la científica puede reclamar esos criterios de validez. Zuluaga (2003) considera la necesidad de adecuar la reflexión pedagógica a las condiciones histórico-pedagógicas de la posmodernidad y el pluralismo cultural y científico. Espinoza Quintana (2002) se inclina a una Pedagogía posmoderna con proyección intercultural. Una consecuencia de esto, según Runge (2002), es el cuestionamiento de un concepto de razón suprahistórica, y la otra, la postulación de una racionalidad relativa, que permita a la Pedagogía definirse y liberarse de la epistemología tradicional, que le objetaba su status de ciencia. Morales Carrillo (2000) habla de una "Epistemología de la transversalidad en educación", que responda a los desafíos de la posmodernidad.

En este bosquejo bibliográfico se encontró propuestas sustentadas en la Teoría de la Complejidad o del Pensamiento Complejo de Edgar Morin, y otros (GALLEGOS TORRES; GALLEGO BADILLO, 2007; GERÔNIMO TELLO, 2004), donde reclama la consideración de la complejidad de la educación y los saberes que en ella se involucran. Según Yanett Polanco B (2006) la asunción de esta perspectiva implica la adopción de una concepción integradora que supera la reducción, disyunción y separación de los conocimientos. Oliva Figueroa (2006) abogó por una Epistemología de la formación de 
profesores, que se base en la complejidad, multidimensionalidad, flexibilidad y pluralidad de los modos de conocimiento potenciados. Gonzalo Gutiérrez (2001), en que lo 1lama "Epistemología de la Investigación Aplicada a la Educación" (versus Epistemología de la Educación), propone asumir que toda realidad, tanto la física como social, es "autopoética" (creativa) y compleja, y que todo conocimiento es hipotético. De ahí entonces, que el hecho educativo debe basarse no en un modelo de racionalidad univoca, objetivista, atomística, sino en un modelo considere el carácter intencional, consciente, constructivo, relacional, conversacional, autopoiético, complejo, y participativo de la práctica educativa.

De forma peculiar esta perspectiva se observa una Epistemología inspirada en el Enfoque Histórico-Cultural de Lev S. Vygotsky, que postula la construcción del conocimiento en educación a partir siempre de la experiencia histórico-social y siempre cambiante del proceso de aprendizaje, su carácter consciente y constructivo, y su mediación lingüística y cultural. Esto significa considerar el papel del lenguaje como mediador de significados sociales y la interacción grupal (CHÁVEZ RODRIGUES, 2010) en el aprendizaje. Todo saber sería entonces valorizado dada a su relación con la actividad. (RAMOS SERPA, 2010) Y esto supone, a tono con el criterio de Valera Alfonso (2003), la superación de la Psicogenética walloniana y también a la Epistemología genética piagetana, por cuanto implica la integración entre lo biológico y lo social, la herencia y el medio, lo afectivo y lo cognitivo en el fenómeno psíquico.

Los Estudios Sociales de la Ciencia y la Tecnología, o de Ciencia, Tecnología y Sociedad (CTS), como se conocen en América Latina de lengua castellana, es desarrollado por autores enfatizan en los condiciones e impactos sociales de las ciencias y las tecnologías. (NÚÑEZ JOVER, 2003) En tal sentido, esos estudios arremeten contra la imagen cientificista y convencional del saber científico, y prácticamente aportaron importantes elementos para considerar la valorización del saber no científico en pie de igualdad con el no científico. (NÚÑEZ JOVER, 2003)

De la Sociología Crítica de Pierre Bourdieu se infiere que la escuela como dispositivo de reproducción social de la dominación y de las desigualdades, se vale de dispositivos de inculcación de un "habitus académico" (prácticas, culturas, saberes), catalogado como legítimo, natural, y racional, que silencia, invisibiliza y estigmatiza el habitus previo y el capital cultural con que los alumnos acceden 
a la escuela. Este efecto de violencia simbólica se traduce en una suerte de imposición de significados, y contempla lo que pudiera llamarse violencia epistemológica contra los saberes excluidos. (FREYRE ROACH, 2009) Esta reflexión de vigilancia epistemológica sustentada en Bourdieu está teniendo gran empuje en la región latinoamericana de lengua castellana. (SEMINARIO..., 2009)

\section{Valorización epistemológica del saber campesino}

No es difícil encontrar en las escuelas modernas, desde el nivel primario hasta la universidad, la desvalorización de los saberes campesinos, presentándolos como inferiores, pues se basan en la mera empiria, la intución sensorial, el sentido cotidiano (común o corriente), la fe ciega, el testimonio ancestral, el método de ensayo y error, cuyo alcance gnoseológico no va más del cómo son y suceden las cosas, y, por lo tanto incapaz de dar cuenta de forma racional de los en si y los por qué (causas, regularidades, y leyes).

Actualmente, la reinvindicación epistemológica del saber campesino se aboga por diferentes encuadres teóricos como la Agroecología (SEVILLA GUZMÁN, 2006), la Bioética (FREYRE ROACH, 2008), los movimientos sociales campesinos como el Movimiento de Trabajadores sin Tierras en Brasil, el Movimiento Zapatista de Liberación Nacional, y la Vía Campesina, la EE sustentada en la Educación Popular de Paulo Freire, etc.

Jesús Nuñez (2008) en su análisis epistemológico de la educación rural en su país, enfatizó que, tanto en la formación como en la investigación, es necesario tomar en cuenta los mundos de la vida personal, social y cultural, y los saberes empíricos, experienciales, ordinarios, cotidianos, concretos, y holísticos de los campesinos, armonizarlos, y sinergizarlos con los conocimientos científicos en los programas educativos (formales y no formales) que se desarrollen en las comunidades rurales. Los investigadores de AGRUCO en Bolivia como Delgado Burgoa (1998), y Burgos Salamanca (2010), abogaron por un diálogo intercultural y convergencia de saberes basado en el mutuo respeto y el aprovechamiento sinérgico de las fortalezas de cada uno de los sistemas de pensamiento. Esta misma propuesta o proyecto de rescate y revalorización del saber campesino se contemplaron entre los objetivos del Centro de Educación y Capacitación en Tecnologías Campesinas (CECTEC) en Paraguay. 
La valorización epistemológica del saber campesino va más allá del análisis crítico y desmistificador de saber científico. Para autores que proponen una especie de Epistemología campesina se trata también de investigar cómo se génera, difunde, dinamiza transforma, y valida ese saber, demostrando que, si se considera su utilidad y funcionamiento, su carácter no estático ni aferrado, cabría de considerarlos científicos a su modo. (SCHMELKES, 1996) Sin embargo, iendo epistemológicamente más lejos, habría que pensar en la busqueda de una legitimación del saber campesino que prescinda de su identificación con el saber científico, pues de lo contrarios se caería en la trampa del reduccionismo positivista.

El mismo riesgo epistemológico se corre si consideramos que esa valorización se pone solo en función de la educación rural, la gestión del desarrollo en los entornos agrarios, campesinos y rurales, la formación de profesionales agrarios, y la defensa de los derechos humanos de los campesinos. La estigmatización, interiorización, y exclusión del saber campesino, opera incluso en la enseñanza en todos los niveles y modalidades, y hasta incluso en la vida cotidiana, por lo tanto, vale también hacia esos otros contextos educativos los esfuerzos de visibilización y valorización del saber campesino.

\section{La valorización epistemológica del saber indígena amerindio y afronegroamericano}

En América Latina va ganado espacio una Epistemología de la educación que se orienta hacia la problemática de la multiculturalidad y la reinvindicación de los saberes de los pueblos amerindios, indígenas, y afronegroamericano.

Es el caso de autores como Javier Gómez Navarrete (2006), que propone discutir sobre a "Epistemologia Ameríndia" de mayas (México), los aymaras (Bolivia), los Sumu (Nicaragua), los Kuna (Panamá), los Cañari (Equador), y otros pueblos, los cuales atesoran formas fructíferas de formar e investigar en su contexto natural, y social cultural específico. Fornet-Betancour (2002) propone la dignificación cognitiva de todas las tradiciones culturales en América Latina como base para una educación intercultural. En su propuesta de decolonización de la ciencia y su enseñanza María Cristina Cifuentes (2009) enfila su crítica hacia lo que 1lama "Ideo-

logía del Universalismo Epistemológico”, en tanto su jerarquización 
de los conocimientos, conduce al silenciamiento de los saberes amerindios tanto en el espacio aúlico como en la conformación e implementación de los currículos.

Al igual que ocurre respecto al saber común y corriente, y al saber campesino, la valorización epistemológica del saber indígena, presupone la atribución de ciertas características o criterios de validéz. Por ejemplo, Pérez Morales (2006), estableciendo distancia entre la racionalidad aristotélica y cartesiana (instrumental, racionalista, objetivista, dualista, deductivista, sustentada en principios como la identidad, exclusión y no contradicción, y orientada hacia la productividad, la competitividad, el dominio o poder, y el lucro), y la racionalidad amerindia, le atribuye a esta última la orientación hacia valores como la contemplación, el deleite de los sentidos, la amistad, la imaginación, la conexión con el mundo, el sentido comunitario y concreto.

La valorización epistemológica del saber amerindio tributa al interés hoy en auge en la educación o alfabetización en la interculturalidad y multiculturalidad, que, a decir de Vilcatoma Salas (2011) contempla la .interculturalización de los componentes cognoscitivos en el diseño curricular.

A esta perspectiva contribuye también lo que, a decir de Morales Domínguez (2006), cuando saca a relucir la cuestión del color o raza del conocimiento y la educación em Cuba. Lo más común es que se imparte e inculca conocimientos, sin considerar los troncos formativos multirraciales africanos y negros de la cultura nacional, es decir, eludiendose a mencionar el color. Este "blanqueamiento" de la enseñanza, según el autor citado, perjudica la autoconciencia racial como la formación no solo de los negros, sino también de los blancos. Reflexiones epistemológicas que se enrumban en tal sentido, por lo general, integran los esfuerzos por uan educación, Pedagogía o alfabetización para la igualdad racial en el espacio escolar y los curriculos.

\section{La valorización epistemológica del saber femenino}

La Epistemología feminista o de género llama la atención en como la enseñanza escolar ha estado atrapada en sesgos sexistas, androcéntricos, patriarcales, machistas, y masculinistas, que se inmiscuyen en la estructura misma del conocimiento científico. Es decir, en pocas palabras, que el conocimiento científico no es 
neutral o imparcial desde el punto de vista de la relaciones de género. Esta pespectiva es desarrollada por autoras y autores latinoamericanos de lengua castellana que llaman la atención a los estereotipos sexistas que se localizan en el lenguaje de la ciencia, y según Diana Maffia (2007), se hace necesaria una especie de "subversión semiótica de las mujeres en los textos escolares.

Para Cabruja Ubach (2008) las relaciones de poder y dominación intergrupales y sexistas actúan de la misma forma en la producción de saberes en Psicología. El punto de vista positivista, no hace más, según esta autora, que atribuir al saber científico una supuesta neutralidad y objetividad, que apuntala la permanencia de un imaginario androcéntrico y etnocéntrico que dificultan la capacidad de cuestionar la Psicología desde las relaciones de poder que la condicionan. Palacio Ibáñez (2009) en su propuesta de Epistemología de Género y de Pedagogía de Género crítica el dualismo entre naturaleza-cultura y hombre-mujer presente en el enfoque epistemológico tradicional de la ciencia, la educación, y los currículos. Pérez Bustos (2010), apoyándose en la concepción de la Educación Popular de Paulo Freire, trabaja la Epistemología Feminista en función de un Proyecto de Popularización de la Ciencia y la Tecnología, donde se subvierta el privilegio que en la construcción social del conocimiento y en la educación se le ha otorgado a valores androcéntricos como la neutralidad, la objetividad y la racionalidad. Al mismo tiempo, ese Proyecto busca la inclusión de otros valores como la subjetividad, la parcialidad, las emociones y sentimientos, el involucramiento, y la improvisación, sugeridos en la experiencia cognoscitiva y práctica de las mujeres.

Los trabajos de valoración epistemológica del saber femenino tributan a lo que Subirats (1998) y Arcos y otros (2006) llaman "Pedagogía de Género", que precisamente someta a crítica la articulación de los estereotipos sexistas y las brechas de género en los textos escolares, en los métodos de enseñanza, en las políticas de educación, la administración escolar y en la producción de conocimientos en educación. Al mismo tiempo se reclama la visibilización e inclusión de las experiencias cognoscitivas y prácticas de las mujeres en los currículos. 


\title{
Consideraciones finales
}

En la década pasada, las valorizaciones epistemológicas de los saberes excluidos exhibieron auge entre las contribuciones latinoamericanas de lengua castellana de la década pasada. Esas valoraciones tributan, ante todo, al desarrollo de la busqueda epistemológica, y representan una ruptura o contrapunteo con el paradigma epistemológico positivista convencional.

Este gesto epistemológico inclusivo de los saberes excluidos plantea un reto no solo epistemológico, científico, y pedagógico, sino también político. ¿Cómo armonizar y sinergizar en un currícu1o, en una clase, en la administración escolar, en la política educacional, en la investigación educacional, y hasta en la vida cotidiana escolar, esos saberes excluidos, junto con los saberes científicos?

Pero más allá de esta cuestión, se trata de la estructuración de un ejercicio de vigilancia epistemológica (FREYRE ROACH, 2009) que tomar en serio las implicaciones que esto tiene para la democratización en los entornos sociales, ya sea en los propiamente educativos, como en los que no lo son, pero si lo son también en última instancia: la familia, la comunidad, el centro de trabajo, los espacios culturales, recreativos, deportivos, y mediáticos.

La descalificación epistemológica de los saberes cotidiano, campesino, amerindio, afronegroamericano, y femenino, lleva inexorablemente a la violencia epistemológica (como variante de la "violencia simbólica escolar" denunciada por Pierre Bourdieu), que a su vez, conduce a la predominancia y perpetuamiento de las relaciones de dominación en el espacio escolar, afectando la potenciación de los capitales humanos, económicos, ecológicos, sociales, y culturales, de los portadores de esos saberes excluidos: el campesino, el obrero, los indígenas, los negros, y las mujeres.

\section{The shift to the excluded knowledge}

\begin{abstract}
The positivist epistemology of education takes the cientifico-natural knowlege as a reference model to think the objectivity, neutrality, the intersubsetividad, universality, and certainty of knowledge. This knowledge that does not fall under this criterion is stigmatized. The article's main objective is to reflect on the knowledge that is excluded. Today shown a broad Latin American intellectual movement of the Castilian language, which at the time put in questioned this epistemological gesture, turned to the epistemological (ontological and explicable) valorization of this knowledge excluded: common knowledge, farmer knowledge, Amerindian indigenous knowledge, know Afro-American, and feminine knowledge.
\end{abstract}

revista entreideias, Salvador, n. 01, p. 27-43, jan./jun. 2012 
Key words: Epistemology of epistemological violence. Epistemological surveillance. Education. Democratization of knowledge.

\section{Referencias}

ABARCA FERNÁNDEZ, Ramón R. Teoría del aprendizaje constructivista. [s.1.: s.n.] 2001. Disponible em: <http://www.ucsm.edu.pe/rabarcaf/ taco02.htm >. Acesso em: 10 nov. 2006.

ADÚRIZ-BRAVO, Agustín. Integración de la epistemologia en la formación del profesorado de ciencias. 2001. Tesis (Doctoral) - Universitat Autónoma de Barcelona, España, 2001.

ANDRADE, Raiza. Hacia una gnoseología del desaprendizaje dialógico cognoconsciente: Principios para desaprender en el contexto de la complejidad. Revista Electrónica e Investigación Educativa, v. 7, n. 2, p. 1-16, 2005. Disponible em: <http://redie.uabc.mx/vol7no2/ contenido-andrade.html > . Acesso em: 4 mayo 2011.

ARCOS, Estela G. et al. Descubriendo el género en el currículo explícito (currículo formal) de la educación del tercer período de la Universidad Austral de Chile 2003-2004. Estudios Pedagógicos, Valdivia, v. 32, n. 1, p. 33-47, 2006. Disponível em: < http://www.scielo.cl/scielo. php? script $=$ sci_arttextEpid $=$ S0718-p. 07052006000100003Elng $=$ esEnr $\mathrm{m}=$ isoEtlng $=$ es $>$. Acesso em: 10 abr. 2011.

ÁRRAGA DE MONTIEL, Marisela; AÑEZ DE BRAVO, Aura. Aprendizaje, enfoques epistemológicos y estilos de pensamiento. Encuentro Educacional, v. 10, n.1, p. 23-37, abr. 2003. Disponível em:<http:// revistas.luz.edu.ve/index.php/ed/issue/view/641 >. Acesso em: 10 abr. 2011.

ARRIARÁN, Samuel. Hermeneutica analogica y educacion multicultural. In: HERNÁNDEZ GARCÍA, Gabriela (Coord.). Hermenéutica, analogía e filosofia actual. México, DF: Facultad de Filosofia y Letras, UNAM, 2007. Disponível em: < http://books.google. $\mathrm{com} /$ books id $=$ cLN_YPOaS84CEpg $=$ PA177\& $\mathrm{dq}=$ samuel + arriaran $\mathcal{E}$ ei $=$ vCfzSaDULpusMp269LcJEhl $=$ es\# $\mathrm{v}=$ onepage $\& \mathrm{q}=$ samuel $\% 20$ arriaranEf $=$ false. $>$ Acesso em: 10 abr. 2011.

BARTOMEU FERNANDO, Monserrat et al. Educación y pedagogía: una sospechosa identidad. Perfiles Educativos, México, DF, n. 75, 1997, enero-marzo 1997. Disponível em: < http://redalyc.uaemex.mx/ pdf/132/13207502.pdf > . Acesso em: 10 jun. 2006.

BEUCHOT, Mauricio. Tratado de hermenéutica analógica. México: UNAM, Facultad de Filosofía y Letras, 1997.

; PRIMERO RIVAS, Luis Eduardo. La hermenéutica analógica de la pedagogía de lo cotidiano. México, DF: Primero Editores, 2003. (Construcción Humana)

BUNGE, Mário Augusto. Epistemologia: curso de atualização. São Paulo: T. A. Queiroz, 1980. 
BURGOS SALAMANCA, Diego Armando. Agroecología y saber local, bases de la educación para vivir. 2010. Disponível em: < http://www. utp.edu.co/php/institutoambiental/Agroecologia_y_saber_local.pdf > . Acesso em: 27 mayo 2010.

CABRUJA UBACH, Teresa. ¿Quién teme a la psicología feminista? Reflexiones sobre las construcciones discursivas de profesores, estudiantes y profesionales de psicología para que cuando el género entre en el aula, el feminismo no salga por la ventana. Pro-Posições, Campinas, SP, v. 19, n. 2, p. 25-46, mayo/ago. 2008.

CALZADILLA, Ramón. La universidad y la emancipación histórica del sujeto racional en la ética de la postmodernidad. Investigación y Postgrado, Caracas, v. 21, n. 2, p. 269-286, 2006.

CHÁVEZ RODRIGUES, Justo. Actualidad de las tendencias pedagógicas. Disponível em: < http://gemini.udistrital.edu.co/comunidad/ profesores/jruiz/jairocd/texto/pedagogia/actualidadte.pdf > . Acesso em: 11 mayo 2010.

CIFUENTES, M. Cristina. Decolonizar la ciencia y su enseñanza. Colombia, 2009. Disponível em:<http://educyt.wikispaces.com/ file/view/Decolonizar + la + ciencia $+\mathrm{y}+\mathrm{su}+$ ense \%C3\%B1 anza.pdf $>$. Acesso em: 11 oct. 2010.

COLOMBO DE CUDMANI, Leonor. ¿Qué puede aportar la epistemología a los diseños curriculares en física? Ciência \& Educação, v. 9, n. 1, p. 83-91, 2003. Disponível em: < http://www.scielo.br/pdf/ ciedu/v9n1/07.pdf>. Acesso em: 4 mayo 2010.

DE ZAN, Maria Elena C. et al. Construcción y validación del conocimiento: la problemática epistemológica en la teoría y práctica educativa. [2007] Disponível em: < http://www.ucsf.edu.ar/investig/ Pfrofessor.HTM\#2 > . Acesso em: 11 fev. 2007.

DELGADO BURGOA, Freddy. El conocimiento científico y el saber local en un dialogo intercultural para el fortalecimiento de la gestion municipal y el desarrollo sostenible. Revista de Agricultura, n. 30, p. 19-25, 1998.

DELGADO DE COLMENARES, Flor. La educación contemporánea entre la racionalidad técnico-instrumental y la emancipación: un intento de aproximación a la obra de Jürgen Habermas. Acción Pedagógica, v. 11, n. 2, p. 4-12, 2002.

ESCHENHAGEN, María Luisa. Retos epistemológicos y teóricos para el curriculum ambiental de posgrados. Avaliação, Campinas, SP; Sorocaba, SP, v. 13, n. 1, p. 119-130, mar. 2008. Disponível em: < http://www. scielo.br/pdf/aval/v13n1/a07v13n1.pdf>. Acesso em: 4 fev. 2011.

ESPINOZA QUINTANA, Luis Alfredo. Primeras reflexiones sobre una pedagogía postmoderna para Latinoamérica. Extramuros, n. 1, p. 51-58, 2002. 
FORNET-BETANCOURT, Raúl. Por una filosofía intercultural desde la América Latina. Cuadernos Hispanoamericanos, n. 627, p. 23-27, sept., 2002.

FREYRE ROACH, Eduardo Francisco. Agricultura y agrotecnologías. In: TEALDI, Juan Carlos. Diccionario latinoamericano de bioética. Bogotá: UNESCO; Universidad Nacional de Colombia, 2008.

La sobrerrepresentación de intelectuales, mujeres y estudiantes de piel blanca en la educación superior cubana: un ejercicio de vigilancia epistemológica: tomando en serio a Pierre Bourdieu. In: SEMINÁRIO INTERNACIONAL "BOURDIEU, EDUCACIÓN Y PEDAGOGÍA". Bogotá: Instituto para la Investigación Educativa y el Desarrollo Pedagógico, 2009. p. 55-78. (Investigación e Innovación). Disponível em: < http://www.idep.edu.co/pdf/Seminario_\%20 internacional_Bourdieu.pdf>. Acesso em: 10 jun. 2006.

GAETA, Rodolfo; ROBLES, Nilda. Nociones de epistemología. Buenos Aires: Eudeba, 1990.

GALLEGO TORRES, Adriana Patricia; GALLEGO BADILLO, Romulo. Historia, epistemología y didáctica: unas relaciones necesarias. Ciência \& Educação, v. 13, n. 1, p. 85-98, 2007.

GALLEGOS, Miguel. La epistemología de la complejidad como recurso para la educacion. [2003] Disponível em: < http://www.ambiente.gov. ar/infotecaea/descargas/gallegos01.pdf> . Acesso em: 22 abr. 2007.

GÓMEZ NAVARRETE, Javier. ?Epistemología amerindia de los mayas?. En: MAERK, Johannes; CABROLIE; Magaly (Coord.). ¿Existe una epistemología latinoamericana? construcción del conocimiento en América Latina y el Caribe. México: \& Plaza y Valdes : Universidad de Quintana Roo, 2006.

GONZALÉZ Y LOBO, Guadalupe et al. Epistemologías regionales: una caracterización (y un corolario educacional). Revista Mexicana de Investigación Educativa, México, v. 4, n. 8, p. 245-271, jul./dic. 1999.

GUTIÉRREZ, Gonzalo. Educación, investigación y políticas en una perspectiva de pensamiento complejo. Temuco: [s.n.], 2001.

HENAO GIL, José Rodolfo. Epistemología y educación: una reflexión desde el contexto de la escuela. Eureka, Universidad del Norte, edición 3, [1995]. Disponível em: < http://www.uninorte.edu.co/publicaciones/ eureka/ > . Acesso em: 24 jul.2007.

HERNÁNDEZ GARCÍA, Gabriela (Coord.). Hermenéutica, analogia y filosofia actual. México, D. F.: UNAM, 2007. Disponível em: < http:// books.google.com/books?id = cLN_YPOaS84CEpg = PA177Edq = samuel + arriaran\&ei $=\mathrm{vCfzSaDULpusMp269LcJE} \mathrm{hl}=\mathrm{es} \# \mathrm{v}=$ onepage\& $\mathrm{q}=\mathrm{samu}$ el\%20arriaran $\& f$ f false. $>$ Acesso em: 10 abr. 2011.

JIMENEZ LOZANO, Blanca. Epistemología y métodos de la ciencia. Perfiles Educativos, México, DF, n. 63, enero-marzo, 1994. 
KLIMOVSKY, Gregorio. Las desventuras del conocimiento científico: una introducción a la epistemología. Buenos Aires: AZ, 1994.

MAFFIA, Diana. Epistemología feminista: la subversión semiótica de las mujeres en la ciencia. Revista Venezolana de Estudios de la Mujer, Caracas, v. 12, n. 28, jun. 2007. Disponível em: < http://www.scielo. org.ve/scielo.php?pid =S1316-37012007000100005\&script = sci_arttext $>$. Acesso em: 5 abr. 2010.

MASSÉ NARVÁEZ, Carlos E. La construcción de objetos socioeducativos con base epistemológica. Sociologias, Porto Alegre, ano 10, n. 19, p. 274301, jan./jun. 2008.

MATURANA, Humberto; VARELA, Francisco. De máquinas y seres vivos: autopoiesis, la organización de lo vivo. Santiago de Chile: Editorial Universitaria, 1995.

MORALES CARRILLO, José Tadeo. Epistemología de la transversalidad. Anthropos, Caracas, n. 40, p. 91-102, 2000.

MORALES DOMÍNGUEZ, Esteban. Cuba: algunos desafíos del color. 2006. Disponível em: < http://www.afrocubaweb.com/News/ algunoisdesafios.pdf > . Acesso em: 11 sept. 2010.

MORENO, Alejandro. Nuevos paradigmas epistemológicos en ciencias sociales. Anthropos, Caracas, n. 41, p. 23-38 jul./dic. 2000.

MOSTERIN, Jesús. Conceptos y teorías de la ciencia. Madrid: AlianzaEditorial, [1984].

MOULINES, Carlos Ulises. Exploraciones metacientíficas: estructura, desarrollo y contenido de la ciência. Madrid: Alianza Editorial, 1982.

NUÑEZ, Jesús. Prácticas sociales campesinas: saber local y educación rural. Investigación y Postgrado, v. 23, n. 2, p. 45-88, ago. 2008.

NÚÑEZ JOVER, Jorge. La ciencia y la tecnología como procesos sociales: lo que la educación científica no debería olvidar. Habana: Varela, 2003.

OLIVA FIGUEROA, Ivan. Sobre epistemología, complejidad y procesos de formación de profesores. Revista Profissão Docente on-line, v. 6, n. 13, 2006. Disponível em: < http://www.revistas.uniube.br/index.php/rpd/ article/view/286 > . Acesso em: 9 abr. 2007.

OROZCO CRUZ, Juan Carlos. Concepciones de investigación en la fomación de docentes. Revista Colombiana de Educación, n. 36-37, enero/dic. 1998. Disponível em:<http://w3.pedagogica.edu.co/>. Acesso em: 15 nov. 2006.

PALACIOS IBÁÑEZ, Loreto. Epistemología y pedagogía de género: el referente masculino: como modo de construcción y transmisión. Horizontes Educacionales, v. 1, 14, n. 1, p. 65-75, 2009. Disponível em:<http://www.redalyc.uaemex.mx/redalyc/ pdf/979/.../97912444005 >. Acceso em: 26 mayo 2010. 
PERAFÁN ECHEVERRI, Gerardo Andrés. La epistemología del profesor sobre su propio conocimiento profesional. Bogotá: Universidad Pedagógica Nacional, 2004.

PÉREZ BUSTOS, Tania. Aportes feministas a la educación popular: entradas para repensar pedagógicamente la popularización de la ciencia y la tecnología. Educação e Pesquisa, v. 36, n. 1, p. 236-242, enero/abr. 2010.

PÉREZ MORALES, Patricia. Educación amerindia: una pedagogía para la vida. Congresso Internacional de Pedagogia Social, 2006, São Paulo. Disponível em: < http://www.proceedings.scielo.br/scielo. php?script $=$ sci_arttextEpid $=$ MSC0000000092006000100042Elng $=$ enE $\mathrm{nrm}=$ iso $>$. Acesso em: 4 mayo 2010.

POLANCO B., Yanet. La epistemología de la complejidad como recurso para la educacion. Revista Ciencias de la Educación Crítica. Valencia, Año 6, v. 1, n. 27, p. 179-188, enero/junio 2006. Disponível em: < http://servicio.bc.uc.edu.ve/educacion/revista/ > . Acesso em: 24 jun. 2012.

RAMOS SERPA, Gerardo. Los fundamentos filosóficos de la educación como reconsideración crítica de la filosofía de la educación. Revista Iberoamericana de Educación, n.36/8, 2010. Disponível em:<http:// www.rieoei.org/deloslectores/1023Ramos.PDF > . Acesso em: 7 feb. 2011.

RETAMOSO RODRÍGUEZ, Gerado. Educación y sociedad. Civilizar, v. 7, n. 12, p. 171-186, enero/jun. 2007.

RINCÓN RAMIREZ, Carlos. La formación de investigadores en educación: retos y perspectivas para América Latina en el siglo XXI. Revista Iberoamericana de Educación, 2004. Disponível em: <www.oei. es/ > . Acesso em: 2 oct. 2006.

RUNGE, Andrés Klaus. Una epistemología histórica de la pedagogía: el trabajo de Olga Lucía Zuluaga. Revista de Pedagogía, Caracas, v. 23, n. 68, p. 361-385, sept. 2002.

SANTIAGO ALZUETA, Héctor Luis et al. Pedagogía y epistemología: una cita con la historia. Revista Mexicana de Investigación Educativa, México, v. 2, n. 3, p. 103-116, enero/jun. 1997.

SCHMELKES, Sylvia. El conocimiento campesino. Revista Mexicana de Investigaciñin Educativa, v. 11, n. 6, p. 333-337, enero/mar. 1996.

SEMINARIO INTERNACIONAL "BOURDIEU, EDUCACIÓN Y PEDAGOGÍA”. Bogotá: Instituto para la Investigación Educativa y el Desarrollo Pedagógico, 2009. (Investigación e Innovación)

SEVILLA GUZMÁN, Eduardo. De la sociologia rural a la agroecología. Barcelona: Icaria, [2006].

SUBIRATS, Marina. La educación de las mujeres: de la marginalidad a la co-educación. Santiago de Chile: CEPAL, 1998. 
GERÓNIMO TELLO, César. La formación docente en Argentina: abordaje epistemológico desde el paradigma de la complejidad. Profesorado, revista de currículum y formación del profesorado, v. 8, n. 1, p. 1-9, 2004. Disponível em: < http://digibug.ugr.es/ bitstream/10481/15202/1/rev81COL1.pdf >. Acesso em: 6 jun. 2012.

UNIVERSIDAD PEDAGOGICA NACIONAL. Virrectoría Académica. Lineamentos teóricos de la práctica educativa para los proyectos curriculares de la UPN. Santafé de Bogotá, 2001.

VALERA ALFONSO, Orlando. Las corrientes de la psicología contemporánea: revisión crítica desde sus orígenes a la actualidad. Ciudad de la Habana: Pueblo y Educación, c2003.

VILCATOMA SALAS, Luis F. Epistemología intercultural y currículo universitário. 2011. Disponível em: < http://www.losandes.com.pe/ Educacion/20110116/45337.html > . Acesso em: 16 jan. 2011.

YARZA DE LOS RÍOS, Alexander. Travesía: apuntes para una epistemología y una pedagogía de la educación especial en Colombia. Revista de Pedagogía, Caracas, v. 26, n. 76, p. 281-305, mayo/ago. 2005.

ZAMBRANO, Armando Leal. Las ciencias de la educación y didática: hermenéutica de una relación culturalmente específica. EDUCERE, Año 10, n. 35, 583-589, oct./nov./dic. 2006.

ZULUAGA, Olga Lúcia. Pedagogía y epistemología. Bogotá: Cooperativa Editorial Magisterio, 2003.

Recebido: 28/03/2012 | Aprovado: 15/04/2012

Eduardo Francisco Freyre Roach: Professor Titular da Universidad Agraria de la Habana (UNAH), doutor em Ciências Filosóficas (1987) e Licenciatura em Ciencias Filosóficas (1983) pela Universidad Estatal de Moscú, ajemabra@yahoo.com.br

Adolfo Ramos Lamar: Professor A4 da Fundação Universidade Regional de Blumenau, doutor em Educação pela Universidade Estadual de Campinas (1998), paulofreire@iar.unicamp.br 